\title{
Factors Associated with Functional Disability Among Lebanese Elderly Living in Rural Areas: Role of Polypharmacy, Alcohol Consumption, and Nutrition-based on the Aging and Malnutrition in Elderly Lebanese (AMEL) Study
}

\author{
Elias Zgheib ${ }^{1}$, Elsy Ramia ${ }^{2}$, Souheil Hallit ${ }^{3,4,5,}$, Christa Boulos ${ }^{6}$, Pascale Salameh ${ }^{1,5,7}$ \\ ${ }^{1}$ Faculty of Pharmacy, Lebanese University, Beirut, Lebanon \\ ${ }^{2}$ School of Pharmacy, Lebanese American University, Byblos, Lebanon \\ ${ }^{3}$ Faculty of Medicine and Medical Sciences, Holy Spirit University of Kaslik (USEK), Jounieh, Lebanon \\ ${ }^{4}$ Research Department, Psychiatric Hospital of the Cross, Jal Eddib, Lebanon \\ ${ }^{5}$ INSPECT-LB: Institut National de Sante Publique, Epidemiologie Clinique et Toxicologie, Beirut, Lebanon \\ ${ }^{6}$ Department of nutrition, Faculty of Pharmacy, Saint Joseph University, Beirut, Lebanon \\ ${ }^{7}$ Faculty of Medicine, Lebanese University, Beirut, Lebanon
}

\section{ARTICLE INFO}

\section{Article History}

Received 15 October 2017

Accepted 8 August 2018

Keywords

Activities of daily living

disability

elderly

functional status

polypharmacy

\begin{abstract}
The objective is to describe disability risk factors in Lebanese elderly living in rural settings, focusing on the role of polypharmacy, alcohol consumption, and nutrition. The Aging and Malnutrition in Elderly Lebanese study, a cross-sectional population-based one (April 2011-April 2012), included 1200 individuals aged $\geq 65$ years from 24 Lebanese rural districts. The results showed that 288 (24\%) were disabled and 287 (23.9\%) exposed to polypharmacy. More disabled participants were found among patients exposed to polypharmacy (40.8\%) than those who were not (18.8\%). Major classes associated with disability were "Parkinson" and "Alzheimer" medications, with "alcohol consumption" being responsible for a major interaction with medications. Chronic diseases, nutrition, and socioeconomic status also had a large effect on disability. Skin ulcer $(\mathrm{ORa}=8.569$; CI 5.330-14.823), followed by dementia (ORa = 3.667; CI 1.167-8.912), and anti-gout drugs $(\mathrm{ORa}=$ 3.962; CI 1.290-7.622) were found to be significantly associated with increased odds of disability the most. Many factors are associated with disability among elderly, including polypharmacy and the association of medications with alcohol. Counseling of the elderly caregivers is warranted.
\end{abstract}

(c) 2018 Atlantis Press International B.V. This is an open access article under the CC BY-NC license (http://creativecommons.org/licenses/by-nc/4.0/).

\section{INTRODUCTION}

Demographic transition has reached Lebanon before any other Arab country, with the percentage (7.4\%) of Lebanese elderly people aged 65 years or more being the highest in the region $[1,2]$. The functional status decline is one of the major complications elderly people may encounter. Different aspects of an elderly life can be affected by this decline. The implications range from a slight decrease in the quality of life at early stages to an increased demand of resources for care and rehabilitation, hospitalization or admission to residential care, and may even evolve to premature death. Thereby, prevention of disability in the elderly is a matter of humanitarian, economic, and public health concern [3]. Moreover, the development of adequate preventive strategies requires an understanding of the mechanisms behind the age-associated decline in the functional status [4].

Generally, disability can be the result of several factors coexisting in the disabled elderly. Predisposing factors of childhood (that

*Corresponding author. Email: souheilhallit@hotmail.com might affect growth and development patterns, which influence muscle formation), followed by contributing factors (physical inactivity, chronic diseases, and malnutrition) during midlife [5], and some environmental changes (difficulty in accessing health services, difficulty leaving home because of architectural barriers, and based on whether signage on roads and walkways is sufficient/ insufficient) [6], may develop in the advanced age into a larger spectrum of parameters such as sarcopenia, low income, social isolation, inadequate lifestyle habits, and medication use $[7,8]$. Moreover, socioeconomic inequity and irregular access to healthcare make the situation more complicated in a transitional country such as Lebanon [9]. Although medications may be linked to disability, few studies have attempted to link disability to medication intake $[10,11]$.

The prevalence of prescribing medications to seniors has increased substantially over the past decade [12]. In fact, prescribed medications are an important contributor to the functional decline in the elderly [13]. In a prospective study of community-dwelling older adults, increased prescription medication use was associated with diminished ability to perform instrumental activities of daily 
living (ADLs) and reduced physical functioning [14]. Multiple potential physiological explanations exist to elucidate the impact of medication [15]. For example, it has been suggested that specific medication may increase the risk for impaired functional status by adversely affecting domains such as alertness, vision, and muscle strength with increased risk of falls and fractures [16]. In addition, potential prescribing problems exist among elderly with dosage, duplication, drug-drug interactions, duration, and drugdisease interactions $[17,18]$. Therefore, prescribing for older people requires careful assessment of benefits and risks for the person's entire medical status [19]. However, drug classes do not have the same level of effect on the functional status. Some classes may have little or no effect; others may cause disability, whereas few drugs are believed to play a protective role [20]. Several studies have shown associations between exposure to certain classes of medications, particularly those with sedative and anti-cholinergic actions, and physical dysfunction in elderly [21,22]. However, the number of medications used, regardless of their category, was associated with a decline in functional status in most studies [23].

Moreover, other than demographic features such as female sex and increasing age [24,25], lifestyle features such as smoking and alcohol consumption, low education, low income, as well as urban dwelling have been associated with increased risk of disability among elderly persons [24,26].

The Aging and Malnutrition in Elderly Lebanese (AMEL) study was primarily conducted to assess the health and nutritional status of community-living elderly people in rural settings in Lebanon [27]. In the present work, the AMEL study database was explored to spot functional disability-associated factors, especially those related to polypharmacy, alcohol consumption, and the nutritional status. To our knowledge, this is the first study describing the health conditions of a large representative sample of elderly Lebanese living in rural areas.

\section{METHODS}

The AMEL is a cross-sectional, population-based study conducted between April 2011 and April 2012, including 1200 communitydwelling elderly individuals living in 24 rural Cazas (districts) of Lebanon. People aged $\geq 65$ years were randomly selected through multistage cluster sampling. Subjects were interviewed at their homes by trained interviewers. A minimum of 1024 subjects was necessary to establish a $95 \%$ confidence interval, with an accuracy of $\pm 3 \%$, taking clustering into account. Due to possible missing values in several items, a final sample size of 1200 elderly persons was chosen.

\subsection{Subjects and Setting}

Lebanon is divided into Mohafazat (governorates), each of which consists of several districts (Cazas) forming a total of 25 Cazas. As our study targeted only rural elderly subjects, the Caza of Beirut (urban area) was excluded. In each of the remaining 24 Cazas (strata), two villages were randomly selected from the list of villages provided by the Central Agency for Statistics in Lebanon, except for two Cazas where only one large village was selected, giving a total of 46 villages.
Within each village, a random sample of 25 elderly individuals was drawn from the small villages and 50 from the larger villages, based on the list of households provided by the municipality or other local authority. The reason for not selecting the number of participants according to proportional allocation is that the number of subjects to be included per village was not known ahead of time due to the lack of data from government authorities; we sometimes had to visit each village and get the population list from the concerned municipality. The number of subjects to be included in each village was adjusted a posteriori. A replacement list was prepared in case of absence or refusal of participation. The inclusion criteria were: to be at least 65 years old, to live at home in rural areas, to be free from any terminal illness, and not be tube-fed.

\subsection{Tools and Techniques}

The study was based on a comprehensive multicomponent interview schedule including the assessment tools as described below. The interview schedule was translated back and forth from French to Arabic by two sworn translators. A pilot study including 100 individuals was performed previously to pretest the feasibility of the interview schedule.

The interview schedule was administered to the participants at their home by trained interviewers. Participants remained anonymous and individual records were kept confidential. The recorded variables included demographic characteristics (age, gender), living conditions (living alone or with others), financial situation, and medical insurance. Weight was measured in light indoor clothes without shoes, by electronic digital scale to the nearest $0.1 \mathrm{~kg}$, whereas height was measured in a standing position to the nearest $0.1 \mathrm{~cm}$. Body mass index (BMI) was computed as weight $(\mathrm{kg}) /$ height $\left(\mathrm{m}^{2}\right)$. Nutritional status was assessed by the mininutritional assessment (18 questions score) in its Arabic version [28]. Comorbidities were recorded by asking participants whether they suffered from chronic physician-diagnosed conditions such as hypertension, diabetes, and so on. Drug intake was assessed by the number of drugs taken daily on a regular basis as prescribed by a physician, and checked with packages shown to the interviewer [27]. Polypharmacy was defined by the number of drugs greater than 6 per participant [29].

Furthermore, the participants were questioned about chronic pain (yes/no), defined as feeling pain for at least 3 months, insomnia (no or occasionally/often or always) as well as recent hospitalization $(<1$ year). Some questions were dedicated to exploring dietary habits, tobacco, and alcohol consumption. Diets were based on the diseases the population declared to have; low-fat diet was defined as a diet to treat hypercholesterolemia and hypertriglyceridemia, whereas the diabetic diet was the diet people followed if they were diabetic. They were assessed by interviewers who were all nutritionists.

Depression was assessed by the 5-item Geriatric Depression Scale (GDS-5) [30], which was validated in its Arabic version [31]. The Lubben Social Network Scale 6 in its abbreviated version was used to investigate the social network $[32,33]$. Finally, subjective loneliness was assessed by the modified version of the Jong Gierveld Loneliness Scale as described by Wilson et al. [34]. 
Among the different scales, the outcome variable studied was the result of the ADL score, which was computed by adding the answers to all the ADL questions, while the most potential explanatory variables were medication factors and health-related predictors. The ADL 5-item scale was used to assess the functional status. ADL is a tool commonly used in comprehensive geriatric assessment evaluating the basic activities such as bathing, toileting, clothing, walking, and eating on his/her own [35]. This scale was validated in its Arabic version by Nasser and Doumit [36] in a sample of Lebanese elderly living in nursing homes. Incontinence was not considered in this scale, because difficulties in bladder or bowel control reflect an abnormality in a particular physical system and should, therefore, be considered as impairment rather than a disability [37]. According to the results, participants were divided into two groups: those who are independent in all 5 items were considered "not disabled," and those who need help to accomplish at least one of the tasks of the score were defined as "disabled."

\subsection{Compliance with Ethical Standards}

The study was approved by the ethics committee of the Saint Joseph's University. Oral consent was obtained from participants before the administration of the interview schedule. Also, participants' identity and individual results were kept confidential.

\subsection{Statistical Analysis}

The Statistical Package for Social Sciences (SPSS) version 23.0 was used to enter and analyze data. Drugs taken by each participant were classified into drug classes and were recorded into new dichotomized variables. We used the Chi-square test in the bivariate analysis. Fisher's Exact, a non-parametric, alternative was used where applicable. Odds ratios with 95\% confidence intervals were calculated. Dependent variable was the functional status dichotomized as "disabled" vs. "not disabled."

Due to the low sample size with regard to the high number of variables to be introduced within the multivariable model, multivariable logistic regression analysis was performed in five separate models: variables were grouped and analysis carried out for every group of independent variables. We introduced on each model the main independent variables that were associated with functional status at $p \leq 0.05$ in the bivariate analysis. In model 1 , all the sociodemographic predictors were introduced simultaneously. Model 2 included chronic diseases-related variables. In model 3, health and medication variables were entered. Model 4 included dietary habits, alcohol, and tobacco consumption were tested additionally. A final model (model 5: the summary) was run with all the variables that were significantly associated with functional status in the previous four models. In the final model, age and polypharmacy were enforced. Checking for interactions was performed on the associations between polypharmacy and ADL, before concluding to the final model: checking for interactions of medications was performed using stratified analysis (testing for OR homogeneity between strata) and introducing the interaction term in the regression model. The same predictors were introduced in a multiple regression model assuming ADL to be a continuous variable, after checking its validity using appropriate testing.

\section{RESULTS}

A total number of 1200 participants was included in our analysis. Baseline characteristics of participants are detailed earlier [27]. The sample included 591 men (49.2\%) and 609 women (50.8\%). The mean age was $75.3 \pm 7.1$ years and similar in both genders. Nearly $60 \%$ of the participants were Christians, $27.7 \%$ were Muslims, and 13.7\% Druze. About 10\% of the elderly individuals lived alone; among these, elderly women were three times more likely to live alone than men. Most of the men (84.8\%), but only $44.2 \%$ of women were still married. Women were two times more likely to be illiterate than men and to suffer from poor financial status. About $46.8 \%$ of the participants had a monthly income of less than $300,000 \mathrm{LL}$ (USD 200), and two thirds were partially or totally dependent on their children. More than $40 \%$ of the study sample did not have any health insurance. Regarding the current work status, nearly $30 \%$ of men were still working.

\subsection{Prevalence of Disability}

The prevalence of disability in the sample was $24 \%$, with $76 \%$ of the study participants being "independent" in terms of functional status. Besides, 287 (23.9\%) elderly persons included in the study were found to be exposed to polypharmacy.

\subsection{Disability According to Sociodemographic Variables}

Citizens of South Lebanon and Nabatieh were observed to have a higher proportion of disabled participants (South $32.2 \%$ and Nabatieh $32.0 \%$ ) as compared with participants living in other governorates $(p=0.001)$. The percentage of disabled individuals was found to double in people older than 80 (18.6\% if age $<80$ vs. $41.1 \%$ if age $\geq 80 . p=0.001)$ and in those living with other individuals in the same house (13.45\% if living alone and $25.2 \%$ if not. $p=0.004$ ). Also, women are significantly more physically dependent than men (27.5\% vs. $20.5 \% p=0.005)$. Nevertheless, the "number of rooms at home" and "having a medical insurance" were not associated with the functional status (Table 1).

\subsection{Health Status and Biometric Variables}

Participants who suffered "insomnia," "chronic pain," described their health status as "bad," were "losing weight involuntarily," "hospitalized" or "have been consulted by their doctor last year", were found to be more disabled than those who have not been in these circumstances $(p=0.001)$. Subjects with thin/normal BMI were at more risk of disability than their overweight fellows (disabled: $27.3 \%$ among thin/normal BMI, 21.0\% among overweight $p=0.025)$. More disabled participants appear among depressive (45.1\%) (vs. 18.1\% among participants with normal GDS-5 results, $p=0.001$ ) and lonely individuals (50.7\%) (vs. $24.0 \%$ among patients with normal Wilson results, $p=0.001$ ). 
Table 1 Percentages of "disabled participants" between different groups of sociodemographic variables

\begin{tabular}{|c|c|c|c|}
\hline \multirow{2}{*}{ Variables } & Disabled & Not disabled & \multirow{2}{*}{$p$-Valu } \\
\hline & $288(24 \%)$ & $912(76 \%)$ & \\
\hline Governorate & & & $<0.001$ \\
\hline Mount Lebanon $n=300$ & $66(22 \%)$ & $234(78 \%)$ & \\
\hline North Lebanon $n=300$ & $53(17.7 \%)$ & $247(82.3 \%)$ & \\
\hline South Lebanon $n=150$ & $48(32.2 \%)$ & $102(67.8 \%)$ & \\
\hline Nabatieh $n=200$ & $64(32.0 \%)$ & $136(68.0 \%)$ & \\
\hline Bekaa $n=250$ & $57(22.8 \%)$ & $197(77.2 \%)$ & \\
\hline Age & & & $<0.001$ \\
\hline$<80$ years $n=910$ & $169(18.6 \%)$ & $741(81.4 \%)$ & \\
\hline$\geq 80$ years $n=290$ & $119(41.1 \%)$ & $171(58.9 \%)$ & \\
\hline Sex & & & 0.005 \\
\hline Male $n=592$ & $121(20.5 \%)$ & $471(79.5 \%)$ & \\
\hline Female $n=608$ & $167(27.5 \%)$ & $441(72.5 \%)$ & \\
\hline Monthly income & & & 0.029 \\
\hline$<600,000 \mathrm{LBP}^{*} n=860$ & $222(25.7 \%)$ & $638(74.3 \%)$ & \\
\hline$>600,000 \mathrm{LBP}^{*} n=340$ & $66(19.4 \%)$ & $274(80.6 \%)$ & \\
\hline $\begin{array}{l}\text { Insurance/National security } \\
\text { coverage }\end{array}$ & & & 0.667 \\
\hline No $n=492$ & $122(24.4 \%)$ & $370(75.6 \%)$ & \\
\hline Yes $n=708$ & $166(23.4 \%)$ & $542(76.6 \%)$ & \\
\hline Lives alone & & & 0.004 \\
\hline No $n=1080$ & $272(25.2 \%)$ & $808(74.8 \%)$ & \\
\hline Yes $n=120$ & $16(13.5 \%)$ & $104(86.5 \%)$ & \\
\hline Number of rooms at home & & & 0.253 \\
\hline$\leq 3$ rooms $n=514$ & $115(22.5 \%)$ & $401(77.5 \%)$ & \\
\hline$>3$ rooms $n=686$ & $173(25.4 \%)$ & $513(74.6 \%)$ & \\
\hline
\end{tabular}

${ }^{*}$ Equivalent to US $\$ 400$.

\subsection{Polypharmacy}

The increasing number of administered drugs was significantly associated with disability as there were more disabled people among participants consuming more than six drugs (polypharmacy) (40.8\%) than among those consuming less than five (18.8\%) $(p<0.001)$. The class of medication taken had also an effect. Taking an atypical antipsychotic, Alzheimer, or Parkinson drug is associated with the highest proportions of disabled participants $(66.7 \%$, $77.9 \%$, and $68.2 \%$, respectively) (Table 2 ).

\subsection{Dietary Habits}

The analysis has finally shown that any kind of "special diet" (lowfat, sodium-free, diabetic, low calories, fluid diet), smoking status, and alcohol consumption were significantly associated with a greater tendency toward disability $(p=0.001)$. Hence, $30.7 \%$ of smokers were disabled, whereas only $20.5 \%$ of nonsmokers were affected by a disability ( $p=0.001)$. The greatest difference was observed between alcohol consumers $(62.8 \%$ were dependent) and participants not drinking alcohol (19.5\% were dependent) $(p=0.001)$ (Table 3$)$.

\subsection{Multivariable Analyses}

The multivariable analysis shows that citizens of Mount Lebanon $(\mathrm{OR}=0.889$; CI $0.466-1.815)$ or North $(\mathrm{OR}=0.801$; CI $0.338-$ $1.545)$ had less disability, whereas living in South $(\mathrm{OR}=1.785$;
Table 2 Percentages of disabled participants with respect to regular drug intake

\begin{tabular}{|c|c|c|c|c|c|}
\hline $\begin{array}{l}\text { Drug intake } \\
\text { (Variables) }\end{array}$ & $\begin{array}{l}\text { Yes/ } \\
\text { No }\end{array}$ & $n$ & $\begin{array}{c}\text { Disabled } \\
(\%)\end{array}$ & $\begin{array}{c}\text { Not } \\
\text { disabled (\%) }\end{array}$ & $p$-Value \\
\hline \multirow[t]{2}{*}{ Polypharmacy } & No & 622 & $117(18.8)$ & $505(81.2)$ & \\
\hline & Yes & 419 & $171(40.8)$ & $248(59.6)$ & \\
\hline \multirow[t]{2}{*}{ Diuretics } & No & 936 & $203(21.7)$ & $733(78.3)$ & $<0.001$ \\
\hline & Yes & 264 & $85(32.2)$ & $179(67.8)$ & \\
\hline \multirow[t]{2}{*}{ Anti-arrhythmic } & No & 951 & $222(23.4)$ & $729(76.4)$ & 0.035 \\
\hline & Yes & 249 & $85(34.2)$ & $164(65.8)$ & \\
\hline \multirow[t]{2}{*}{ Anti-coagulants } & No & 802 & $170(21.2)$ & $632(78.8)$ & $<0.001$ \\
\hline & Yes & 398 & $118(29.6)$ & $280(70.4)$ & \\
\hline \multirow[t]{2}{*}{ Anti-ischemic } & No & 1072 & $237(22.1)$ & $835(77.9)$ & $<0.001$ \\
\hline & Yes & 128 & $51(39.8)$ & $77(60.2)$ & \\
\hline \multirow[t]{2}{*}{ Oral anti-diabetics } & No & 901 & $191(21.2)$ & $710(78.8)$ & $<0.001$ \\
\hline & Yes & 292 & $97(33.2)$ & $195(66.8)$ & \\
\hline \multirow[t]{2}{*}{ Insulin } & No & 1178 & $278(23.6)$ & $900(76.4)$ & 0.018 \\
\hline & Yes & 22 & $10(45.5)$ & $12(54.5)$ & \\
\hline \multirow[t]{2}{*}{ NSAID $^{\mathrm{b}}$} & No & 986 & $216(21.9)$ & $770(78.1)$ & $<0.001$ \\
\hline & Yes & 214 & $72(33.6)$ & $142(66.4)$ & \\
\hline \multirow[t]{2}{*}{$\mathrm{PPI}^{\mathrm{c}}$} & No & 1015 & $213(21.0)$ & $802(79.0)$ & $<0.001$ \\
\hline & Yes & 185 & $74(40.0)$ & $111(60.0)$ & \\
\hline \multirow[t]{2}{*}{ Laxatives } & No & 1186 & $281(23.7)$ & $905(76.3)$ & 0.011 \\
\hline & Yes & 12 & $7(58.3)$ & $5(41.7)$ & \\
\hline \multirow[t]{2}{*}{ Anti-cholinergic } & No & 1170 & $272(23.2)$ & $898(76.8)$ & $<0.001$ \\
\hline & Yes & 30 & $16(53.3)$ & $14(46.7)$ & \\
\hline \multirow{2}{*}{$\begin{array}{l}\text { Vitamins } \\
\text { supplements }\end{array}$} & No & 930 & $199(21.4)$ & $731(78.6)$ & $<0.001$ \\
\hline & Yes & 270 & $89(33.0)$ & $181(67.0)$ & \\
\hline \multirow[t]{2}{*}{ Anti-gout } & No & 1161 & $265(22.8)$ & $896(77.2)$ & $<0.001$ \\
\hline & Yes & 39 & $23(59.0)$ & $16(41.0)$ & \\
\hline \multirow{2}{*}{$\begin{array}{l}\text { Typical/atypical } \\
\text { antipsychotics }\end{array}$} & No & 1191 & $282(23.7)$ & $909(76.3)$ & 0.008 \\
\hline & Yes & 9 & $6(66.7)$ & $3(33.3)$ & \\
\hline \multirow[t]{2}{*}{$\mathrm{SSRI}^{\mathrm{d}}$} & No & 1174 & $277(23.6)$ & $897(76.4)$ & 0.027 \\
\hline & Yes & 26 & $11(42.3)$ & $15(57.7)$ & \\
\hline \multirow[t]{2}{*}{ Alzheimer drugs } & No & 1191 & $281(23.6)$ & $900(76.4)$ & $<0.001$ \\
\hline & Yes & 9 & $7(77.9)$ & $2(82.1)$ & \\
\hline \multirow[t]{2}{*}{ Parkinson drugs } & No & 1178 & $286(24)$ & $905(76)$ & $<0.001$ \\
\hline & Yes & 99 & $15(68.2)$ & $7(31.8)$ & \\
\hline \multirow[t]{2}{*}{ Muscle relaxants } & No & 1184 & $278(23.5)$ & $906(76.5)$ & $<0.001$ \\
\hline & Yes & 16 & $10(62.5)$ & $6(37.5)$ & \\
\hline
\end{tabular}

a Only variables significantly associated with disability were shown in this table; bon steroidal anti-inflammatory drugs; 'Proton pump inhibitors; ${ }^{\mathrm{d} S p e c i f i c ~ s e r o t o n i n ~ r e u p t a k e ~ i n h i b i t o r s . ~}$

Table 3 Association of disability to diet types and lifestyle variables

\begin{tabular}{lrcc}
\hline Diet or habit & $\begin{array}{c}\text { Disability } \\
(\text { \%) }\end{array}$ & $\begin{array}{c}\text { No disability } \\
(\mathbf{\%})\end{array}$ & p-Value \\
\hline Sodium-free diet $n=658$ & $196(29.8)$ & $462(70.2)$ & $<0.001$ \\
No sodium-free diet $n=570$ & $98(17.2)$ & $472(82.8)$ & \\
Low-fat diet $n=433$ & $150(34.6)$ & $283(65.4)$ & $<0.001$ \\
No low-fat diet $n=763$ & $135(17.7)$ & $628(82.3)$ & \\
Diabetes diet $n=444$ & $153(34.5)$ & $291(65.5)$ & $<0.001$ \\
No diabetes diet $n=750$ & $132(17.6)$ & $618(82.4)$ & \\
Low-calories diet $n=299$ & $107(35.8)$ & $192(64.2)$ & $<0.001$ \\
No low-calories diet $n=894$ & $178(19.9)$ & $716(80.1)$ & \\
Fluid diet $n=185$ & $83(44.9)$ & $102(55.1)$ & $<0.001$ \\
No fluid diet $n=1010$ & $202(20.0)$ & $808(80.0)$ & \\
Alcohol consumption $n=121$ & $76(62.8)$ & $45(37.2)$ & $<0.001$ \\
No alcohol consumption $n=1072$ & $209(19.5)$ & $863(80.5)$ & \\
Smoking $n=407$ & $125(30.7)$ & $282(69.3)$ & $<0.001$ \\
No smoking $n=790$ & $162(20.5)$ & $628(79.5)$ & \\
\hline
\end{tabular}

This table contains an exhaustive list of the factors that have entered the study from this section. 
CI 1.166-4.881) or in Nabatieh (OR = 2.395; CI 0.977-5.228) was associated with higher rates of dependence. Logistic regressions also showed that having some chronic diseases can be associated with an increased risk of being disabled; thus, any chronic disease is considered to be a risk factor toward functional status decline. "Skin ulcer" $(\mathrm{OR}=8.660$; CI 3.311-15.822) and "amputated member" ( $\mathrm{OR}=9.589$; CI 3.158-20.147) were the chronic impairments that would increase disability the most. If we examine the effect of medications, we can see that when we performed the logistic regression on all drug classes, five remained in the equation: anti-ischemic, proton pump inhibitors (PPIs), laxatives, anti-gout, and antiparkinson medications. Antiparkinson medications were by far the class of medications that would increase disability the most $(\mathrm{OR}=11.590$; CI 5.699-23.277) (Table 4).

Table 4 Impact of potential correlates on functional status (ADL): logistic regressions

\begin{tabular}{|c|c|c|c|c|c|}
\hline & \multirow{2}{*}{$B$} & \multirow{2}{*}{ Sig. } & \multirow{2}{*}{ OR } & \multicolumn{2}{|c|}{$95 \%$ CI for $\exp (B)$} \\
\hline & & & & Lower & Upper \\
\hline \multicolumn{6}{|c|}{ Model 1: Chronic diseases } \\
\hline Hypertension & 0.344 & 0.049 & 1.411 & 1.001 & 1.988 \\
\hline Diabetes & 0.479 & 0.005 & 1.614 & 1.154 & 2.257 \\
\hline Cardiac problem & 0.357 & 0.047 & 1.429 & 1.005 & 2.032 \\
\hline Rheumatoid arthritis & 0.326 & 0.093 & 1.385 & 0.947 & 2.025 \\
\hline Parkinson & 1.216 & 0.008 & 3.372 & 1.375 & 8.268 \\
\hline Gastric problem & 0.783 & $<0.001$ & 2.188 & 1.480 & 3.234 \\
\hline Hearing impairment & 0.772 & $<0.001$ & 2.163 & 1.511 & 3.099 \\
\hline Skin ulcer & 2.159 & 0.012 & 8.660 & 1.615 & 46.437 \\
\hline Amputation & 2.26 & 0.009 & 9.589 & 1.764 & 52.122 \\
\hline Hyperuricemia & 0.878 & 0.033 & 2.405 & 1.074 & 5.384 \\
\hline Dementia & 1.126 & $<0.001$ & 3.083 & 1.635 & 5.810 \\
\hline Fracture & 0.762 & 0.005 & 2.142 & 1.259 & 3.645 \\
\hline \multicolumn{6}{|c|}{ Model 2: Health status, biometric variables and medication } \\
\hline Anti-ischemic & 0.606 & 0.041 & 1.833 & 1.026 & 3.276 \\
\hline PPIs & 0.688 & 0.006 & 1.990 & 1.213 & 3.265 \\
\hline Laxatives & 1.679 & 0.075 & 5.360 & 0.846 & 33.936 \\
\hline Anti-gout & 1.201 & 0.025 & 3.324 & 1.165 & 9.487 \\
\hline Parkinson drugs & 2.450 & 0.006 & 11.590 & 1.985 & 67.668 \\
\hline Insomnia & 0.476 & 0.026 & 1.610 & 1.059 & 2.448 \\
\hline Consults doctor & 0.702 & 0.001 & 2.018 & 1.308 & 3.112 \\
\hline Depression & 0.566 & 0.013 & 1.761 & 1.124 & 2.760 \\
\hline Malnutrition & 1.026 & $<0.001$ & 2.789 & 1.769 & 4.397 \\
\hline Loneliness & 0.676 & 0.003 & 1.965 & 1.264 & 3.055 \\
\hline \multicolumn{6}{|c|}{ Model 3: Diet and habits } \\
\hline Smoking & 0.536 & $<0.001$ & 1.710 & 1.276 & 2.290 \\
\hline Smoking period & -0.428 & 0.009 & 0.652 & 0.474 & 0.897 \\
\hline Diabetic diet & 0.419 & 0.014 & 1.520 & 1.089 & 2.122 \\
\hline Fluid diet & 0.413 & 0.060 & 1.512 & 0.983 & 2.324 \\
\hline Alcohol & 1.541 & $<0.001$ & 4.668 & 2.967 & 7.344 \\
\hline
\end{tabular}

Model 1: Omnibus test $(p=0.001)$, Hosmer/Lemshow $(p=0.549)$ tests and the classification table $(77.1 \%)$ show that the model is adequate to reality and that at least one chronic disease has an effect on the functional status. Also, 22.8\% (Nagelkerke $R$-square) of the variance of the functional status can be explained by chronic diseases. Model 2: Omnibus test $(p=0.001)$, Hosmer/Lemshow $(p=0.314)$ tests and the classification table $(75.4 \%)$ show that the model is adequate to reality and that at least one variable has an effect on the functional status. Also, $31.4 \%$ (Nagelkerke $R$-square) of the variance of the functional status can be explained by the health status, biometric variables, and medication. Model 3: Omnibus test $(p=0.001)$, Hosmer/Lemshow $(p=0.955)$ tests and the classification table (79\%) show that the model is adequate to reality and that at least one diet habit has an effect on the functional status. Also, 15.7\% (Nagelkerke R-square) of the variance of the functional status can be explained by diet habits. In each model, the factors that were retained in the final model were exclusively displayed in the table; PPIs, proton pump inhibitors.
After checking for interactions with medications to be associated with disability, the interaction with "alcohol consumption," was found to be the only one responsible for a potential quantitative interaction influencing the relationship between "polypharmacy" and "disability"; results were found to be significant in both stratified analysis and logistic regression (when introducing the interaction term). This interaction was significant both on clinical and statistical levels (Homogeneity test: 0.020/RR1 $=2.421[1.742-$ $3.364] /$ RR2 $=8.432[3.002-23.686])$. Multivariate analysis was thus performed in strata (Table 5). Two items namely, "antiparkinson drugs" and "amputation" were excluded from the model for their extreme correlations. In fact, extreme correlation with other variables can lead to collinearity.

Polypharmacy $(\mathrm{OR}=2.087$; CI 1.099-8.367), two drug classes namely, PPI $[\mathrm{OR}=1.731$; CI $0.922-7.663 ; p$ value $=0.075)$ and anti-gout drugs $[\mathrm{OR}=3.962$; CI 1.116-9.624] and 16 other variables (most of them were chronic diseases) appeared in the final model of the entire sample. "Skin ulcer" had highly significant association ( $\mathrm{OR}=8.569$; CI 5.330-14.823), followed by "Dementia" (OR = 3.667; CI 1.167-8.912) and "anti-gout drugs" $(\mathrm{OR}=3.962$; CI 1.290-7.622). The results were similar when regression was performed selectively on participants who did not drink alcohol with almost the same items and with similar OR values.

However, five items were removed from the second model (arthritis, Parkinson, hearing impairment, polypharmacy and PPI) and one new item was added (cerebrovascular disease OR $=1.648$ ) (Table 5). Furthermore, when using ADL as a continuous variable, several factors that showed significance in the logistic regression remained significant in the multiple regression, namely, age, cerebrovascular disease, skin ulceration, dementia, fracture,

Table 5 Summary logistic regression model: disability correlates among Lebanese elderly

\begin{tabular}{|c|c|c|c|c|c|c|}
\hline \multirow{2}{*}{ Variables } & \multicolumn{3}{|c|}{ Whole sample } & \multicolumn{3}{|c|}{ Not drinking alcohol } \\
\hline & $B$ & Sig. & OR & $B$ & Sig. & OR \\
\hline Age & 1.066 & $<0.001$ & 2.904 & 1.012 & 0.000 & 2.752 \\
\hline Live alone & -1.22 & 0.007 & 0.295 & -0.831 & 0.061 & 0.436 \\
\hline $\begin{array}{l}\text { Cerebrovascular } \\
\text { disease }\end{array}$ & - & - & - & 0.500 & 0.063 & 1.648 \\
\hline $\begin{array}{l}\text { Rheumatoid } \\
\text { arthritis }\end{array}$ & -0.538 & 0.074 & 0.584 & - & - & - \\
\hline Parkinson drugs & 1.180 & 0.087 & 3.253 & - & - & - \\
\hline Gastric disease & 0.561 & 0.071 & 1.753 & 0.811 & 0.007 & 2.250 \\
\hline $\begin{array}{l}\text { Hearing } \\
\quad \text { impairment }\end{array}$ & 0.447 & 0.088 & 1.563 & - & - & - \\
\hline Skin ulcer & 2.148 & 0.085 & 8.569 & 2.174 & 0.083 & 8.795 \\
\hline Dementia & 1.299 & 0.027 & 3.667 & 1.364 & 0.015 & 3.911 \\
\hline Fracture & 0.731 & 0.049 & 2.077 & 0.793 & 0.055 & 2.209 \\
\hline Polypharmacy & 0.736 & 0.007 & 2.087 & - & - & - \\
\hline $\begin{array}{l}\text { Proton pump } \\
\text { inhibitors }\end{array}$ & 0.549 & 0.075 & 1.731 & - & - & - \\
\hline Anti-gout & 1.377 & 0.032 & 3.962 & 1.357 & 0.065 & 3.883 \\
\hline $\begin{array}{l}\text { Nutritional } \\
\text { status }\end{array}$ & 0.736 & 0.005 & 2.088 & 0.589 & 0.026 & 1.803 \\
\hline Loneliness & 0.559 & 0.026 & 1.749 & 0.480 & 0.075 & 1.616 \\
\hline Diabetes diet & 0.422 & 0.098 & 1.525 & 0.546 & 0.038 & 1.726 \\
\hline $\begin{array}{l}\text { Alcohol } \\
\text { consumption }\end{array}$ & 0.993 & 0.003 & 2.698 & - & - & - \\
\hline
\end{tabular}


polypharmacy, and diabetic diet were associated with lower ADL; living alone and having a better nutritional status with a higher ADL; whereas alcohol consumption had no significant effect on ADL (Table 6).

\section{DISCUSSION}

According to our database findings, the prevalence of disability in Lebanese elderly is $24 \%$. In 2012, disability occurred in $20.1 \%$ of the participants in a Japanese study directed by Yoshida et al. [38]. The percentage of polypharmacy among our study participants (24\%) was found to be in line with the available literature where polypharmacy of the included elderly [39-41] in ambulatory settings and nursing homes ranged between $15 \%$ and $37 \%$.

The association found between polypharmacy and the functional status decline acts through different hypothetical pathways. First, most people using more than six drugs suffer from multiple chronic diseases, which can be the actual predictor. Second, another possible mechanism can be explained by the frequent kidney and liver intoxication that can be induced by polypharmacy. Finally, some medications can alter the cognitive and brain balance centers and lead to fall risks and subsequent fractures. Polypharmacy has been and will always be a common problem that health care professionals face among the elderly population because of the multiple diseases that develop as the patient ages. Unfortunately, with this increase in the use of multiple medications comes an increased risk for negative health outcomes such as higher healthcare costs, ADEs, drug-drug interactions, medication non-adherence, decreased functional status, and geriatric syndromes. More efforts are needed to try to minimize the number of unnecessary drugs taken by the elderly [42].

However, the medication classes can be as important as the number of medications taken. According to our findings from the bivariate and multivariate analyses, anti-Alzheimer and antiparkinson drugs were the most associated medications with lower dependency. The association between "Parkinson drugs" and disability can be related to the dyskinesia they can cause on long-term use, especially with Levodopa; however, we cannot overlook the fact that the disease itself could be the reason of the disability, not the treatment (this is what we found in the multiple regression). Furthermore, "Alzheimer drugs" may be associated with the functional status decline through "Alzheimer disease."

Table 6 Multiple regression model: disability correlates among Lebanese elderly

\begin{tabular}{lrrr}
\hline & \multicolumn{3}{c}{ Whole sample } \\
\cline { 2 - 4 } Variables & \multicolumn{1}{c}{$\boldsymbol{B}$} & Adjusted $\boldsymbol{B}$ & $\boldsymbol{p}$-Value \\
\hline Age & -0.017 & -0.121 & $<0.001$ \\
Live alone & 0.281 & 0.085 & $<0.001$ \\
Cerebrovascular disease & -0.948 & -0.136 & $<0.001$ \\
Skin ulcer & -0.687 & -0.072 & 0.002 \\
Dementia & -0.425 & -0.091 & $<0.001$ \\
Fracture & -0.233 & -0.064 & 0.006 \\
Polypharmacy & -0.027 & -0.083 & 0.001 \\
Nutritional status & 0.098 & 0.428 & $<0.001$ \\
Diabetes diet & -0.123 & -0.055 & 0.025 \\
Alcohol consumption & 0.093 & 0.059 & 0.116 \\
\hline
\end{tabular}

For other factors, we will discuss multivariate results selectively. One of the most effective factors was found to be living in rural areas in the governorates of Nabatieh and South Lebanon. Indeed, several studies reported that elderly people living in poorer areas suffer from poor health conditions, are less educated, have lower income, and limited access to transport and healthcare $[43,44]$. Moreover, chronic diseases are associated directly or indirectly with disability, as most of the chronically ill patients require special care, diet, and support. Having an amputated limb, for example, makes it very difficult to accomplish the ADL without any help. Twenty-eight percent experienced problems finding work because of amputation [45]. Several factors had a negative impact on reemployment and disability, including but not limited to the amputation level [46], number of amputations [47], comorbidity [48], reason for amputation [48], phantom pain [48], walking distance, and restrictions in mobility [48].

However, "skin ulcer" is inversely linked to physical dependency. In this case, lack of movement (therefore dependency) is the etiology of skin ulcer and not its consequence. This consolidates the summary of a systematic review [49], demonstrating that immobilization and bed rest increased the risk of pressure ulcer development; however, the former can also affect several other organ systems such as the cardiovascular system (orthostatic hypotension, changes in body fluids, reduced oxygen intake, etc.) [50,51], respiratory system (pneumonia, atelectasis, hypoxia) [50,51], musculoskeletal system (muscle atrophy, loss of muscle strength) [50], osteoporosis and bone loss [51,52].

Finally, diet habits were also connected directly or indirectly to the functional status decline. Surprisingly, all types of "healthy" diets (low-fat, sodium-free, etc.) were accompanied by a greater occurrence of disability. In fact, the chronic conditions and diseases leading to the prescription of such diets can be a factor of confusion here. The association of smoking with disability is logical for the effects tobacco has on the nervous system.

For social related variables, we first found that the percentage of disabled individuals was higher among those living with other people than among those living alone, but later loneliness was significantly associated with disability. This finding is expected as independent individuals have a higher possibility of living alone, whereas dependent individuals cannot do it. However, loneliness is well-documented to be associated with a motor decline among community-dwelling older persons $[53,54]$.

The greatest disparity was observed around "alcohol consumption": in both bivariate and multivariate analyses, "drinking alcohol" is proved to be a major factor of dependency with a significant difference between groups. Knowing its physiological properties and social consequences, alcohol can have a direct impact on the functional status decline [55]. However, alcohol and polypharmacy alike may cause hepatotoxicity and can be implicated in some routes leading to disability (drug metabolism, for example). Moreover, alcohol can interact with "depressed mood," "living alone," "smoking," "nutrition," and a multitude of other variables. Alcohol can also increase the risk of falls and potentiates the effect of several medications.

The summary model (applied on the entire sample) has attributed a very small part of the disability to the medications. Only two drug categories remained in the final equation: "PPI" and "anti-gout drugs." This can be explained according to a different hypothesis 
for PPIs and anti-gout separately. In fact, many disabling conditions, such as the decreased absorption of some minerals (Calcium, Iron, and Magnesium) and vitamins (B12), and the increased risk of cardiovascular events and infections are associated with the use of PPIs [56]. As to anti-gout drugs, the explanation may be the reduced action of one of allopurinol's major active metabolite (oxipurinol) on xanthine oxidase by age. This metabolite, no longer sufficiently active in aged persons, causes disability due to gout-related symptoms and becomes more likely to reappear and to disable the patient [57]. Most other items of the final models are chronic diseases. Interestingly, the effect of polypharmacy, visible in the entire population, has disappeared among people who do not drink alcohol. This reinforces the hypothesis of hepatotoxicity or other "alcohol-drug" interaction; further studies are needed to shed light on this phenomenon.

To our knowledge, this is the first community-based study investigating the functional status in a rural setting. The major strengths of our study include the evaluation of a large sample with a comprehensive assessment of numerous variables potentially linked to the functional status. However, several limitations have to be considered. For some drugs, the number of users was very low; this could lead to a low power of some correlations and wide confidence intervals and hamper the conclusion for some associations. First, the cross-sectional observational study design does not allow drawing causal relationship. Second, although our random sample can be considered as a representative, we cannot perform weighting to provide estimates of prevalence for the entire Lebanese population. Furthermore, potential cognitive disorders, lack of memory, and educational disparities may create some recall bias. In addition, some issues affect the private sphere, and responses to these questions suffer from less reliability. Moreover, most of the health-related information was self-reported. Besides this, several instruments were initially developed in the Western culture and therefore may not be culturally sensitive to Lebanon; this may generate some information bias. Finally, there may be some unrecognized factors and remaining residual bias. We suggest further research that takes into account all these limitations to confirm our findings.

\section{CONCLUSION}

In summary, the prevalence of disability in our study was $24 \%$ and the association of medications with the overall functional status was shown to be multifactorial. The major associations found between medications and disability may be related to both the chronic disease itself and its treatment. However, taking a "Parkinson drug" remained independently a major risk factor of dependency. The other major factors associated with disability were mainly chronic diseases and conditions such as having an amputated limb. Moreover, being a woman, or being poor, older than 80 , lonely, depressed, malnourished or thin, smoking, and drinking alcohol increased the chances of being disabled. Most importantly, "alcohol consumption" can affect the association between medication and ADL through hepatotoxicity or any other hypothetical "alcoholdrug" interaction.

In terms of health and social policy, this study has several implications. Appropriate healthcare measures are necessary to reduce the contribution of chronic diseases, as noted by the medication classes taken by each patient, on disability. As socioeconomic status is associated with poorer functional status, it is imperative to ensure pensions for elderly and to guarantee healthcare coverage plans. Moreover, optimal drug prescription with avoidance of unnecessary medications, screening for drug-drug and drug-alcohol interactions and personalization of medication therapy are important measures to take. These practices fall under the responsibility of the pharmacist and other healthcare providers. Finally, the functional status decline in elderly, being a burden on the society: government, families, healthcare providers, and other activists should collaborate to reduce its effect.

\section{AUTHORS' CONTRIBUTION}

Elias Zgheib analyzed the results, drafted the manuscript, and approved its final form.

Elsy Ramia edited the manuscript and contributed to the discussion.

Souheil Hallit edited the manuscript and contributed to the discussion; he is also the corresponding author.

Christa Boulos supervised the study design and data collection, contributed to the manuscript writing and approved its final form.

Pascale Salameh co-supervised the study design and data analysis and finalized the manuscript.

\section{FUNDING}

The Council of research of the Saint-Joseph University provided the financial support for data collection, but had no role in the design, analysis and interpretation of the data; writing of the report; and decision to submit the article for publication.

\section{CONFLICTS OF INTEREST}

The authors declared no potential conflicts of interest with respect to the research, authorship, and/or publication of this article.

\section{REFERENCES}

[1] Population Division of the Department of Economic and Social Affairs of the United Nation Secretariat, World population prospects: the 2008 revision. Available from: http:// kczx.shupl.edu.cn/download/786444c9-20c1-4b5a-b0d6d7544569a2ee.pdf.

[2] Sibai AM, Sen K, Baydoun M, Saxena P. Population ageing in Lebanon: current status, future prospects and implications for policy. Bull World Health Organ 2004;82;219-25.

[3] Heikkinen E. What are the main risk factors for disability in old age and how can disability be prevented. Copenhagen: WHO Regional Office for Europe; 2003.

[4] Guralnik JM, Ferrucci L. Underestimation of disability occurrence in epidemiological studies of older people: is research on disability still alive? J Am Geriatr Soc 2002;50;1599-601. 
[5] Heppenstall CP, Wilkinson TJ, Hanger HC, Keeling S. Frailty: dominos or deliberation? N Z Med J 2009;122;42-53.

[6] do Carmo JF, Oliveira ERA, Morelato RL. Functional disability and associated factors in elderly stroke survivors in Vitória, Brazil. Rev Bras Geriatr Gerontol 2016;19;809-18.

[7] Owens NJ, Silliman RA, Fretwell MD. The relationship between comprehensive functional assessment and optimal pharmacotherapy in the older patient. DICP 1989;23;847-54.

[8] Stuck AE, Walthert JM, Nikolaus T, Büla CJ, Hohmann C, Beck JC. Risk factors for functional status decline in communityliving elderly people: a systematic literature review. Soc Sci Med 1999;48;445-69.

[9] Hosseinpoor AR, Bergen N, Kunst A, Harper S, Guthold R, Rekve D, et al. Socioeconomic inequalities in risk factors for non communicable diseases in low-income and middle-income countries: results from the World Health Survey. BMC Public Health 2012;12;912.

[10] Masoro EJ. Caloric restriction and aging: controversial issues. J Gerontol A Biol Sci Med Sci 2006;61;14-19.

[11] Ruggiero C, Ferrucci L. The endeavor of high maintenance homeostasis: resting metabolic rate and the legacy of longevity. J Gerontol A Biol Sci Med Sci 2006;61;466-71.

[12] Bajcar JM, Wang L, Moineddin R, Nie JX, Tracy CS, Upshur RE. From pharmaco-therapy to pharmaco-prevention: trends in prescribing to older adults in Ontario, Canada, 19972006. BMC Fam Pract 2010;11;75.

[13] Lord SR, Menz HB, Tiedemann A. A physiological profile approach to falls risk assessment and prevention. Phys Ther 2003;83;237-52.

[14] Cadigan DA, Magaziner J, Fedder DO. Polymedicine use among community resident older women: how much a problem? Am J Public Health 1989;79;1537-40.

[15] Thwaites JH. Practical aspects of drug treatment in elderly patients with mobility problems. Drugs Aging 1999;14;105-14.

[16] Mort JR. Geriatric primer: implications and management of decline for the elderly patient. Consult Pharm 2009;24;611-25.

[17] Hanlon JT, Fillenbaum GG, Kuchibhatla M, Artz MB, Boult C, Gross CR, et al. Impact of inappropriate drug use on mortality and functional status in representative community dwelling elders. Med Care 2002;40;166-76.

[18] Knapp DA, Erwin WG. Screening criteria for outpatient drug use review. Baltimore: Center on Drugs and Public Policy, University of Maryland; 1992.

[19] Hilmer SN, Mager DE, Simonsick EM, Ling SM, Windham BG, Harris TB, et al. Drug burden index score and functional decline in older people. Am J Med 2009;122;1142-49.e1-e2.

[20] Lawlor DA, Patel R, Ebrahim S. Association between falls in elderly women and chronic diseases and drug use: cross sectional study. BMJ 2003;327;712-17.

[21] Landi F, Russo A, Liperoti R, Cesari M, Barillaro C, Pahor M, et al. Anticholinergic drugs and physical function among frail elderly population. Clin Pharmacol Ther 2007;81;235-41.

[22] Gray SL, Penninx BW, Blough DK, Artz MB, Guralnik JM, Wallace RB, et al. Benzodiazepine use and physical performance in community-dwelling older women. J Am Geriatr Soc 2003;51;1563-70.

[23] Peron EP, Gray SL, Hanlon JT. Medication use and functional status decline in older adults: a narrative review. Am J Geriatr Pharmacother 2011;9;378-91.
[24] McCurry SM, Gibbons LE, Bond GE, Rice MM, Graves AB, Kukull WA, et al. Older adults and functional decline: a cross-cultural comparison. Int Psychogeriatr 2002;14;161-79.

[25] Ostchega Y, Harris TB, Hirsch R, Parsons VL, Kington R. The prevalence of functional limitations and disability in older persons in the US: data from the National Health and Nutrition Examination Survey III. J Am Geriatr Soc 2000;48;1132-35.

[26] Parahyba MI, Veras R, Melzer D. Disability among elderly women in Brazil. Rev Saúde Pública 2005;39;383-90.

[27] Boulos C, Salameh P, Barberger-Gateau P. The AMEL study, a cross sectional population-based survey on aging and malnutrition in 1200 elderly Lebanese living in rural settings: protocol and sample characteristics. BMC Public Health 2013;13;573.

[28] MNA Arabic form. Available from: http://www.mna-elderly. com/forms/MNA_arabic.pdf.

[29] Bushardt RL, Massey EB, Simpson TW, Ariail JC, Simpson KN. Polypharmacy: misleading, but manageable. Clin Interv Aging $2008 ; 3 ; 383-89$.

[30] Rinaldi P, Mecocci P, Benedetti C, Ercolani S, Bregnocchi M, Menculini G, et al. Validation of the five-item geriatric depression scale in elderly subjects in three different settings. J Am Geriatr Soc 2003;51;694-98.

[31] Hallit S, Hallit RR, Boulos C, Hachem D, Kheir N, Salameh P, et al. Validation of the Arabic geriatric depression scale (GDS-5) among the Lebanese geriatric population. J Psychopathol 2017;23;87-90.

[32] Lubben JE. Assessing social networks among elderly populations. Fam Community Health 1988;11;42-52.

[33] Lubben J, Blozik E, Gillmann G, Iliffe S, von Renteln Kruse W, Beck JC, et al. Performance of an abbreviated version of the Lubben Social Network Scale among three European communitydwelling older adult populations. Gerontologist 2006;46; 503-13.

[34] Wilson RS, Krueger KR, Arnold SE, Schneider JA, Kelly JF, Barnes LL, et al. Loneliness and risk of Alzheimer disease. Arch Gen Psychiatry 2007;64;234-40.

[35] Katz S, Ford AB, Moskowitz RW, Jackson BA, Jaffe MW. Studies of illness in the aged. The index of ADL: a standardized measure of biological and psychosocial function. JAMA 1963;185;914-19.

[36] Nasser R, Doumit J. Validity and reliability of the Arabic version of activities of daily living (ADL). BMC Geriatr 2009;9;11.

[37] Spector WD. Functional disability scales. In: Spilker B, editor. Quality of life assessments in clinical trials, New York: Raven Press Ltd.; 1990, p. 115-29.

[38] Yoshida D, Ninomiya T, Doi Y, Hata J, Fukuhara M, Ikeda F, et al. Prevalence and causes of functional disability in an elderly general population of Japanese: the Hisayama study. J Epidemiol 2012;22;222-29.

[39] Qato DM, Alexander GC, Conti RM, Johnson M, Schumm P, Lindau ST. Use of prescription and over-the-counter medications and dietary supplements among older adults in the United States. JAMA 2008;300;2867-78.

[40] Dwyer LL, Han B, Woodwell DA, Rechtsteiner EA. Polypharmacy in nursing home residents in the United States: results of the 2004 National Nursing Home Survey. Am J Geriatr Pharmacother 2010;8;63-72.

[41] Bronskill SE, Gill SS, Paterson JM, Bell CM, Anderson GM, Rochon PA. Exploring variation in rates of polypharmacy across long term care homes. J Am Med Dir Assoc 2012;13; 309.e15-e21. 
[42] Maher Jr RL, Hanlon J, Hajjar ER. Clinical consequences of polypharmacy in elderly. Expert Opin Drug Saf 2014;13; $57-65$.

[43] Hartley D. Rural health disparities, population health, and rural culture. Am J Public Health 2004;94;1675-78.

[44] McNaughton SA, Crawford D, Ball K, Salmon J. Understanding determinants of nutrition, physical activity and quality of life among older adults: the Wellbeing, Eating and Exercise for a Long Life (WELL) study. Health Qual Life Outcomes 2012;10;109.

[45] Schoppen T, Boonstra A, Groothoff JW, de Vries J, Goeken LN, Eisma WH. Employment status, job characteristics, and work-related health experience of people with a lower limb amputation in The Netherlands. Arch Phys Med Rehabil 2001;82;239-45.

[46] Hebert JS, Ashworth NL. Predictors of return to work following traumatic work-related lower extremity amputation. Disabil Rehabil 2006;28;613-18.

[47] Whyte AS, Carroll LJ. A preliminary examination of the relationship between employment, pain and disability in an amputee population. Disabil Rehabil 2002;24;462-70.

[48] Schoppen T, Boonstra A, Groothoff JW, van Sonderen E, Göeken LN, Eisma WH. Factors related to successful job reintegration of people with a lower limb amputation. Arch Phys Med Rehabil 2001;82;1425-31.
[49] Coleman S, Gorecki C, Nelson EA, Closs SJ, Defloor T, Halfens $\mathrm{R}$, et al. Patient risk factors for pressure ulcer development: systematic review. Int J Nurs Stud 2013;50;974-1003.

[50] Harper CM, Lyles YM. Physiology and complications of bed rest. J Am Geriatr Soc 1988;36;1047-54.

[51] Rousseau P. Immobility in the aged. Arch Fam Med 1993;2; 169-77; discussion 178.

[52] Bloomfield SA. Changes in musculoskeletal structure and function with prolonged bed rest. Med Sci Sports Exerc 1997;29;197-206.

[53] Hawkley LC, Thisted RA, Cacioppo JT. Loneliness predicts reduced physical activity: cross-sectional \& longitudinal analyses. Health Psychol 2009;28;354-63.

[54] Buchman AS, Boyle PA, Wilson RS, et al. Loneliness and the rate of motor decline in old age: the Rush Memory and Aging Project, a community-based cohort study. BMC Geriatr 2010;10;77.

[55] Samokhvalov AV, Popova S, Room R, Ramonas M, Rehm J. Disability associated with alcohol abuse and dependence. Alcohol Clin Exp Res 2010;34;1871-78.

[56] Corsonello A, Maggio M, Fusco S, Adamo B, Amantea D, Pedone C, et al. Proton pump inhibitors and functional decline in older adults discharged from acute care hospitals. J Am Geriatr Soc $2014 ; 62 ; 1110-15$.

[57] Turnheim K, Krivanek P, Oberbauer R. Pharmacokinetics and pharmacodynamics of allopurinol in elderly and young subjects. Br J Clin Pharmacol 1999;48;501-9. 